\title{
THERMAL ANALYSIS OF AN EARTH ENERGY BANK
}

\author{
Muyiwa A. Oyinlola ${ }^{1 *}$, Carlos Naranjo-Mendoza ${ }^{1,2}$, Sakellariou Evangelos ${ }^{1}$, Andrew J. Wright ${ }^{1}$, Richard \\ M. Greenough ${ }^{1}$ \\ ${ }^{1}$ Institute of Energy and Sustainable Development, De Montfort University, Leicester, LE1 9BH United Kingdom \\ ${ }^{2}$ Departamento de Ingeniería Mecánica, Escuela Politécnica Nacional, Ladrón de Guevara E11-253, Quito, \\ Ecuador
}

\section{INTRODUCTION}

Buildings account for about $40 \%$ of the overall energy demand in the EU, and low grade thermal energy, for space heating and domestic hot water, is a significant percentage of this demand [1]. Solar energy is no doubt a clean and affordable source of low temperature heat, however, its variability, positive correlation with external temperature and lack of dispatchability are problematic to use it for domestic heating. In recent times however, research and development in thermal energy storage technologies has promoted the viability of solar energy as a domestic heating source.

One of such developments is a novel Solar Assisted Ground Source Heat Pump system developed by Caplin Homes. The system comprises a Geothermal Heat Exchanger (GHE) which is actually a very shallow borefield (1.5-metre depth) of 16 boreholes, called an Earth Energy Bank (EEB), and hybrid Photovoltaic/Thermal (PVT) collectors. The PVT collectors coproduce electricity which is fed directly into the grid, and heat which is put into the ground via the GHE. The concept of storing thermal energy in the ground using GHEs has been studied by many such as [2], [3] \& [4], however, the depths of these boreholes are usually in excess of $10 \mathrm{~m}$. The peculiarity of the design in this study is in the very shallow depth, which makes it susceptible to the effects of ambient conditions[5].

This paper reports on experimental and computational studies which were carried out to characterize the thermal performance of a lab scale EEB. This study further evaluates the influence of various operation parameters, such as flow rate, temperature and operation interval, on radial/axial soil temperature distribution.

\section{METHDOLOGY}

A 3-D conjugate heat transfer model of a single U-tube heat exchanger was conducted using commercial CFD package, Ansys Fluent. The $25 \mathrm{~mm}$ inner diameter U-tube was placed inside a $150 \mathrm{~mm}$ diameter cylinder of grout which was placed in a $700 \mathrm{~mm}$ by $560 \mathrm{~mm}$ by $950 \mathrm{~mm}$ container of soil. Simulations were run to study the profile after 8 hours of heat transfer to the soil; this was to represent heat transfer on a perfect sunny day. The model was set up to simulate convection from the fluid to the U-tube inner surface, a conjugate heat transfer between the tube outer surface and the grout material as well conduction in the soil.

An experimental test rig was designed, to validate the numerical simulations. The test rig, illustrated in Figure 1 , consisted of a U-tube placed inside a tub of soil, with a grout material as an interface. Water was used as the thermal working fluid; this was supplied at constant temperature and flow rate by a circulating bath. Temperatures of the soil and grout at different points $\left(T_{s i}\right)$ as well as fluid at inlet $\left(T_{i n}\right)$ and fluid at outlet $\left(T_{\text {out }}\right)$, were measured using Type $T$ thermocouples. One thermocouple was placed inside the inlet and outlet ports after elbow fittings (for fluid mixing) to allow accurate readings of bulk fluid temperature. The volumetric flow rate $(\dot{V})$ was measured using an ultrasonic flow meter. All the measured quantities were logged with a 32-bit National Instruments data acquisition system (NI 9174) via Labview. Thermocouples were connected through a NI 9213 thermocouple interface board. Signals were recorded at 5 minutes interval. Sensors were calibrated before installation and signal quality was studied using an oscilloscope to ensure they were clean and free from interference. 


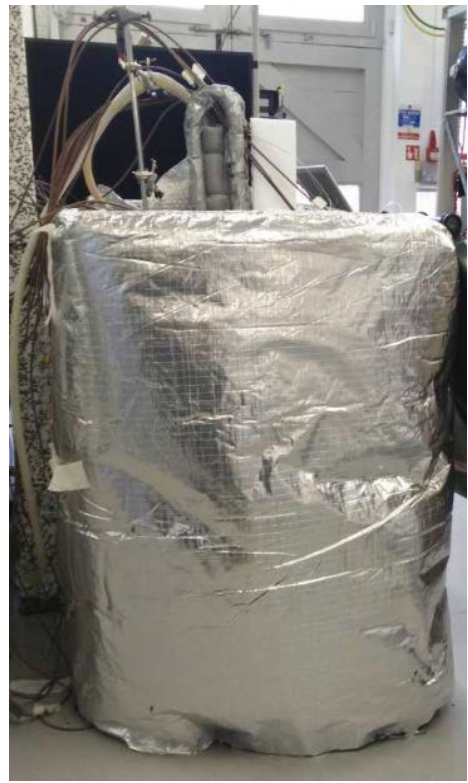

(a)

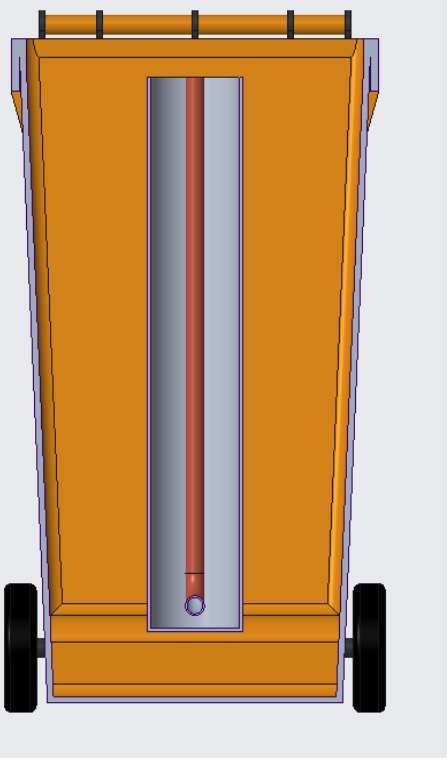

(b)

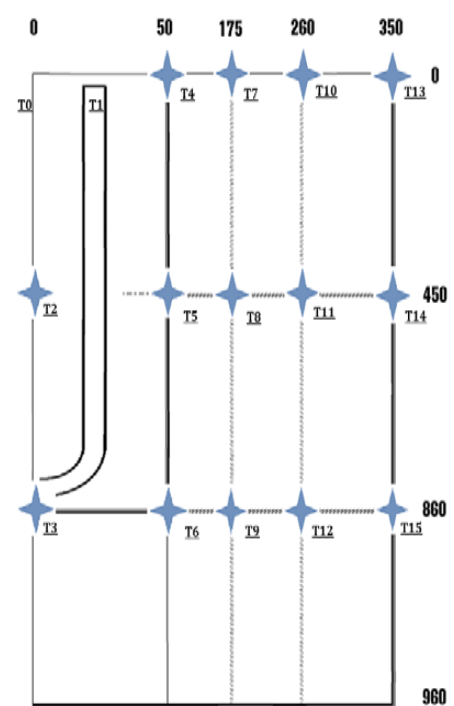

(c)

Figure 1 (a) Experimental test rig (b) Schematic (c) Thermocouple Positions

\section{RESULTS}

Temperature and heat flux data from the experiments showed good agreement with results from the computational study. Figure 2 below shows an example of vertical and horizontal temperature profile after 8 hours. The results showed that in the short term (8hours), the main heat transfer field is within $10 \mathrm{~cm}$, while the thermal interference region is within a radius of $20 \mathrm{~cm}$. The profile between a radius of $20 \mathrm{~cm}$ and the boundary, which is at radius $35 \mathrm{~cm}$, showed a relatively constant temperature. This profile suggests significant thermal resistance between grout material and the soil. This indicates that these shallow boreholes should be closely spaced out. A quick thermal response was observed in the grout, with its temperature reaching steady state within 2 hours. However, the thermal response of the soil was much slower. An increase in soil temperature improves the overall performance of the system and improves the long term thermal balance of the soil. A negligible temperature drop in the working fluid, regardless of the flow rate, was observed after about 4 hours. This low temperature drop has also been observed in full size installations. Three flow rates, 1,2 and 4 liters per minute were studied, the results showed that the effect of flow rate is only significant in the first hour, as all 3 flow rates had similar results after a few hours. Despite some insulation to the sides, it was observed that ambient conditions had some effect on the temperature profile.

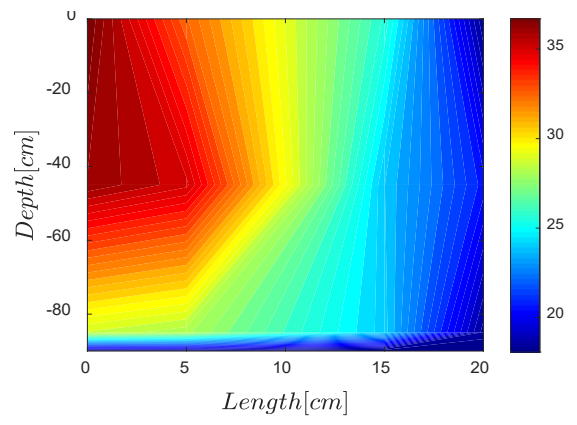

(a)

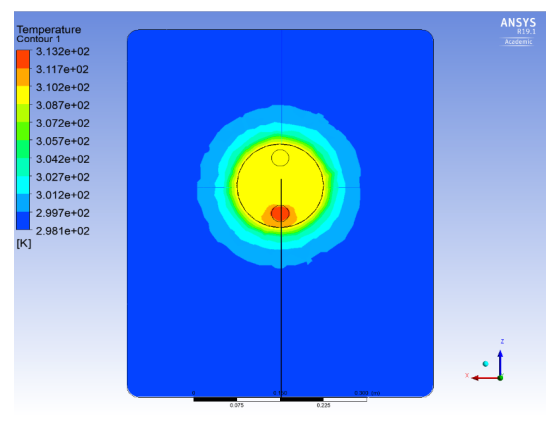

(b)

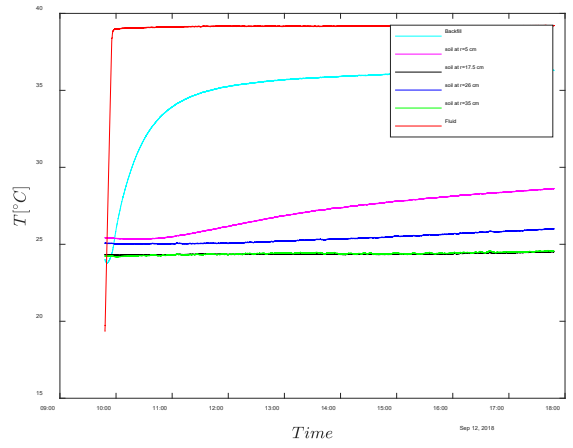

(c)

Figure 2 (a) Vertical temperature profile from experiment (b) Horizontal temperature profile from simulation (c) Horizontal Temperatures profile at $45 \mathrm{~cm}$ depth at 4 liters per minute flow rate 


\section{CONCLUSIONS}

This paper aimed to characterise the performance of very shallow borehole heat exchangers by conducting numerical and experimental analyses. The Ansys Fluent numerical model was validated with experimental data, which illustrates its suitability for further study, such as investigation of different grout materials. The results showed good heat transfer in the backfill material, however the temperature profile observed in the soil showed a very narrow region of heat transfer, indicating that boreholes need to be closely spaced in practical installations. The effect of increasing the flow rate was also studied and found to contribute marginal improvements. The results of the study will be significant in the design and operation of future Earth Energy Bank installations.

\section{REFERENCES}

[1] A. Bertrand, R. Aggoune, and F. Maréchal, "In-building waste water heat recovery: An urban-scale method for the characterisation of water streams and the assessment of energy savings and costs," Appl. Energy, vol. 192, pp. 110-125, 2017.

[2] L. Zhu, S. Chen, Y. Yang, and Y. Sun, "Transient heat transfer performance of a vertical double U-tube borehole heat exchanger under different operation conditions," Renew. Energy, vol. 131, pp. 494-505, Feb. 2019.

[3] L. H. Dai, Y. Shang, X. L. Li, and S. F. Li, "Analysis on the transient heat transfer process inside and outside the borehole for a vertical U-tube ground heat exchanger under short-term heat storage," Renew. Energy, vol. 87, pp. 1121-1129, Mar. 2016.

[4] X. Li, C. Tong, L. Duanmu, and L. Liu, "Study of a U-tube heat exchanger using a shape-stabilized phase change backfill material," Sci. Technol. Built Environ., vol. 23, no. 3, pp. 430-440, Apr. 2017.

[5] C. Naranjo-Mendoza, A. J. Wright, M. A. Oyinlola, and R. M. Greenough, "A comparison of analytical and numerical model predictions of shallow soil temperature variation with experimental measurements," Geothermics, vol. 76, 2018. 